\title{
Determination of the botanical origin of honeybee honeys based on the analysis of their selected physicochemical parameters coupled with chemometric assays
}

\author{
Ewa Majewska ${ }^{1}$ (D) Beata Drużyńska ${ }^{1} \cdot$ Rafał Wołosiak $^{1}$
}

Received: 8 March 2018/Revised: 21 February 2019/Accepted: 5 March 2019/Published online: 6 April 2019

(C) The Author(s) 2019

\begin{abstract}
The aim of this paper was to study the select physicochemical parameters of 58 honey samples of 4 different botanical origins (buckwheat, linden, rape and acacia) using multivariate methods in order to classify honeys according to the botanical origin. Five standard physicochemical parameters were determined according to the international legislation: water content, electrical conductivity, total ash content, free acidity and $\mathrm{pH}$. The results obtained were mostly in agreement with international regulations. Then, the results obtained were analysed by principal components analysis and cluster analysis. The chemometric analysis of results of determinations of the physicochemical parameters demonstrated such markers as electrical conductivity and ash content (i.e. parameters linked with minerals content) to be the most reliable markers in determining the botanical origin of linden and buckwheat honeys. Unfortunately, they appear insufficient for reliable identification of acacia and rapeseed honeys.
\end{abstract}

Keywords Honey · Ash · Electrical conductivity · Chemometric $\cdot$ Botanical origin

Ewa Majewska

ewa_majewska1@sggw.pl

Beata Drużyńska

beata_druzynska@sggw.pl

Rafał Wołosiak

rafal_wolosiak@sggw.pl

1 Division of Food Quality Evaluation, Department of Biotechnology, Microbiology and Food Evaluation, Faculty of Food Sciences, Warsaw University of Life Sciences SGGW, 159 Nowoursynowska Str., 02-787 Warsaw, Poland

\section{Introduction}

Honey is the natural sweet substance produced by Apis mellifera bees from the nectar of plants or from secretions of living parts or excretion of plant-sucking insects on the living parts of plants, which the bees collect, transform by combining with specific substances of their own, deposit, dehydrate, store and leave in honeycombs to ripen and mature (Council EU, 2001). Honey contains more than 200 substances, including amino acids, enzymes, protein, vitamins, minerals, ash, organic acids and phenol compounds (Bueno-Costa et al., 2016). Properties and compositions of bee honey depend strongly on the type of flowers the bees visited, season, on the climatic conditions in which the plants grow and treatment of beekeepers (El Sohaimy et al., 2015).

Botanical authenticity is one of the key problems in honey quality control because it directly affects its market price. Regulating bodies, food industry, retail sellers, and consumers are interested in knowing the origin and quality of honeys available on the market. Investigations on honey authenticity are conducted in many countries worldwide. One of the first methods used to determine the botanical and geographical origin of honeys was pollen analysis (El Sohaimy et al., 2015). However, this technique is time consuming and requires special personnel skill (Jandrić et al., 2015; Popek et al., 2017; Wang and Qing, 2011). For this reason, attempts are undertaken to introduce other analytical methods into the identification process of the origin of honeybee honeys. Hence, determination of the physicochemical parameters conducted in the routine assessment of honey is the most common method for detection of is origin (Juan-Borrás et al., 2014). Studies are underway on the use of various combinations of these parameters that would allow for determining the botanical 
origin of different types of honeys (Karabagias et al., 2014; Rodríguez Flores et al., 2015). To enable evaluation of honey authenticity, works are in progress to develop practical alternative methods and markers for determination of the botanical and geographical origin of this product.

Considering that many different compounds have been detected in honey, its evaluation should be perceived as a multi-variate analysis. Therefore the coupled use of physicochemical parameters and chemometric analyses is a method applied to determine the origin of both honey as well as other food products (Oroian et al., 2015; 2016). The use of chemometry in this case results from the fact that it is a discipline of science and technology of extracting useful information from multi-dimensional measurement data, using statistical and mathematical methods. It differs from the statistics not only in the character of the analyzed variables, but also in the mode of their analysis. Typical statistical methods have been developed to enable the analysis of single variables or of a small number of variables. By principle, the chemometric approach assumes the simultaneous analysis of many variables. Chemometric methods are increasingly often applied to identify natural groups of variables based on their similarity with analytical samples. There are many chemometric techniques of classification, the most common of which include: principal component analysis (PCA), linear discrimination analysis (LDA), cluster analysis (CA) (Juan-Borrás et al., 2014; Oroian et al., 2015; 2016), artificial neutral network (ANN), adaptive neutron-fuzzy inference (ANFIS) (Oroian 2015) and Classification \& Regression Tree (C\&RT) method for data exploration (Popek et al., 2017). The use of these methods allows reducing the complexity of large data sets and offers their better interpretation and understanding.

The objective of this study was an attempt of coupling determinations of parameters linked with the content of mineral compounds and chemometric analysis to identify the botanical origin of honeybee honeys.

\section{Materials and methods}

\section{Chemicals}

The potassium chloride $(\mathrm{KCl})$ and sodium hydroxide $(\mathrm{NaOH})$ were obtained from Avantor Performance Materials Poland S.A. (Gliwice, Poland).

\section{Samples}

A total of 58 honey samples were used for this study. Honey samples were directly obtained in 2015 from the private producers located in the whole territory of the Republic of Poland. The honey samples with different production origin and varieties have been collected. The variety of types of nectar honeys had been investigated: rape, buckwheat, willow and acacia. The botanical origin of honey samples were verified using a pollen analysis with the use of method established by the International Commission of Bee Botany. All samples were immediately transferred to the laboratory and kept stored unpasteurised at $4-5{ }^{\circ} \mathrm{C}$ in the dark.

\section{Determination of moisture}

Water content (moisture) was determined based on the refractometric method using an Abbé-type refractometer (PZO, Warsaw, Poland) and the readings were further corrected for a standard temperature of $20^{\circ} \mathrm{C}$ by adding the correction factor of $0.00023 /{ }^{\circ} \mathrm{C}$. The honey samples that were crystalized at the moment of analysis were previously heated until $40{ }^{\circ} \mathrm{C}$. Moisture content was determined in triplicate and the $\%$ moisture content values corresponding to the corrected refractive index values were calculated using Wedmore table.

\section{Determination of electric conductivity}

Electrical conductivity (EC) of a honey solution at $20 \mathrm{~g} /$ $100 \mathrm{~g}$ (dry matter basis) in $\mathrm{CO}_{2}$-free-deionised water was measured at $20{ }^{\circ} \mathrm{C}$ in a Crison Basic 30 conductimeter (Crison Instruments S.A., Barcelona, Spain). The instrument was calibrated using $0.01 \mathrm{M} \mathrm{KCl}$. The results were expressed as $\mathrm{S} / \mathrm{cm}$. All measurements were performed in triplicate.

\section{Determination of ash content}

Total ash content was determined according to the method of incineration of honey samples. About $5 \mathrm{~g}$ of honey was placed in combustion pots, which required preheating to darkness in electric cooker to prevent honey foaming. Then, the samples were incinerated at a temperature of $550{ }^{\circ} \mathrm{C}$ in a muffle furnace (Carbolite Gero Ltd., Hope Valley, United Kingdom) for $18 \mathrm{~h}$. After cooling at room temperature, the obtained ash was weighed. All measurements were performed in triplicate.

\section{Determination of acid and $\mathrm{pH}$ parameters}

Free acidity was determined by potentiometric titration. Honey samples were homogenized in a water bath before analysis. About $10 \mathrm{~g}$ of honey were dissolved in $75 \mathrm{~mL}$ of $\mathrm{CO}_{2}$ - free distilled water. The solution was titrated with $0.05 \mathrm{~mol} / \mathrm{L} \mathrm{NaOH}$ to $\mathrm{pH}$ 8.30. Free acidity was determined 
in triplicate, The results were expressed in miliequivalent of acid per kilogram of honey. $\mathrm{pH}$ measurements were performed potentiometricaly a $20{ }^{\circ} \mathrm{C}$ using a $\mathrm{pH}$-meter HANNA HI 931400 (HANNA Instruments, Woonsocket, Rhode Island, USA) in a $10 \%(\mathrm{w} / \mathrm{v})$ solution of honey prepared with $\mathrm{CO}_{2}$-free distilled water. All measurements were performed in triplicate.

\section{Statistical analysis}

Analyses were made in triplicate and the data are presented as mean \pm standard deviation. Correlations were obtained by Pearson's correlations between total ash and electrical conductivity. Multivariate analysis [principal component analysis (PCA) and cluster analysis (CA)] was performed by using STATISTICA version 13.1 (StatSoft Poland). Prior the chemometric processing the data matrix were standardised.

To classify honeys according to the physicochemical parameters, cluster analysis was applied. This method is frequently used to screen data for clustering of samples. The main goal of the hierarchical agglomerative cluster analysis was to spontaneously classify the data into groups of similarity (cluster), searching objects in the n-dimensional space located in the closest neighborhood and to separate a stable cluster from other clusters (Simeonov et al., 2007). Cluster analysis was displayed in order to find similarities between the honey samples and also between the variables. Then we were able to check if on that basis they create clusters and we could observe any similarities. In order to do that, Ward's hierarchical cluster method for pattern recognition was used.

Using cluster analysis it was possible to display the object similarity in a reliable way and make the initial interpretation of the data set structure. But a more reliable method proved to be PCA. PCA was used to achieve a reduction of dimension, covering the maximum amount of variability present in the data and to observe a primary evaluation of the between-class similarity. This method provides a new variable as linear combinations of the original descriptor, which are called principal components (Simeonov et al., 2007). Principal component analysis was used as a descriptive tool to visualize the data in two dimensions, founding relationships between the variables and the type of honey. Classical principal component analysis on covariance matrix was used. It was used to search data trends and to provide a partial view of the data in a space with reduced number of dimensions while preserving most of their variability.

\section{Results and discussion}

The results from the physicochemical analysis for the fiftyeight honey samples are presented in Table 1.

Water content of honey is deemed a very important parameter being indicative of improper storage conditions or of potential adulteration of honey in the production process (Fechner et al., 2016). On the other, moisture content may differ between honeys depending on the source of nectar or weather conditions in the region the honey is produced in. Therefore, values of this parameter may change from season to season and also from year to year. European (Council EU, 2001) and international standards (Codex Alimentarius, 2001) stipulate the maximum value of moisture content of honeys at $20 \%(\mathrm{w} / \mathrm{w})$. Most of the honeys analyzed in our study had moisture content below $20 \%$, but in 12 of them it was exceeded (Table 1). In the case of buckwheat honeys, these were samples B12 and B16 (21.1\% and 20.2\%, respectively); in the case of linden honeys-samples L7 and L8 (21.1\% and $20.3 \%$, respectively); in the case of rapeseed honeyssamples R10 (20.2\%), R12 (21.1\%), R14 (21.3\%), R15 (20.2\%), R16 (20.6\%), R18 (20.1\%) and R20 (20.3\%); and in the case of acacia honeys-samples A3 and A6 (20.2\% and $20.1 \%$, respectively). These exceedings can result from weather conditions prevailing while acquiring honey and from its immaturity resulting from early acquiring. The higher water content may lead to undesirable fermentation of honey during its storage as a result of the activity of osmotolerant yeast synthesizing ethyl alcohol and carbon dioxide. Alcohol may be further oxidized to acetic acid and water, thereby contributing to the sour taste of honey (Fechner et al., 2016; Habib et al., 2014; Pita-Calvo and Vázquez, 2017).

Electrical conductivity of honey is strictly linked with contents of their mineral salts and organic acids (Grigoryan, 2016; Habib et al., 2014). It shows the greatest variability among the physicochemical parameters of honeys depending on their botanical origin and therefore enables discriminating between nectar and honeydew honeys (Pita-Calvo and Vázquez, 2017). The measurement of electrical conductivity is part of the routine control of honey and has recently replaced determination of ash content in the international (Codex Alimentarius, 2001) and European standards (Council EU, 2001), to finally become the most common method for honey origin identification (El Sohaimy et al., 2015). Values of electrical conductivity measured in the analyzed honeys and presented in Table 1 did not exceed the maximum value of $800 \mathrm{~S} / \mathrm{cm}$ stipulated in the EU Directive (Council EU, 2001). In samples of buckwheat and linden honeys mean values accounted for $389 \mathrm{~S} / \mathrm{cm}$ and $398 \mathrm{~S} / \mathrm{cm}$, respectively, 
Table 1 Physico-chemical parameters of analysed honey samples (buckwheat $=\mathrm{B}$, linden $=\mathrm{L}$, rape $=\mathrm{R}$ and acacia $=\mathrm{A}$ )

\begin{tabular}{|c|c|c|c|c|c|}
\hline Samples honey & Water content $(\%)$ & Electrical conductivity (S/cm) & Total ash content $(\%)$ & Free acidity (meq/kg) & $\mathrm{pH}$ \\
\hline B1 & 16.7 & 367 & 0.12 & 70.8 & 3.81 \\
\hline B2 & 18.3 & 411 & 0.15 & 84.1 & 3.93 \\
\hline B3 & 19.0 & 746 & 0.37 & 71.2 & 4.07 \\
\hline B4 & 18.3 & 291 & 0.09 & 59.1 & 3.80 \\
\hline B5 & 18.6 & 380 & 0.13 & 67.4 & 3.82 \\
\hline B6 & 18.7 & 332 & 0.11 & 64.8 & 3.85 \\
\hline B7 & 17.5 & 400 & 0.15 & 91.3 & 3.78 \\
\hline B8 & 17.4 & 347 & 0.13 & 66.7 & 3.77 \\
\hline B9 & 19.3 & 428 & 0.17 & 87.4 & 3.78 \\
\hline B10 & 17.4 & 427 & 0.16 & 75.5 & 3.96 \\
\hline B11 & 19.5 & 110 & 0.04 & 28.7 & 3.80 \\
\hline B12 & 21.1 & 421 & 0.16 & 91.4 & 3.78 \\
\hline B13 & 19.5 & 499 & 0.25 & 61.2 & 4.02 \\
\hline B14 & 19.5 & 357 & 0.12 & 75.7 & 3.92 \\
\hline B15 & 18.1 & 429 & 0.16 & 65.0 & 3.89 \\
\hline B16 & 20.2 & 380 & 0.14 & 57.2 & 3.94 \\
\hline B17 & 19.8 & 290 & 0.08 & 42.8 & 4.20 \\
\hline Mean & 18.8 & 389 & 0.15 & 68.3 & 3.89 \\
\hline SD & 1.1 & 122 & 0.07 & 16.1 & 0.12 \\
\hline L1 & 19.5 & 226 & 0.05 & 34.7 & 3.87 \\
\hline L2 & 17.0 & 537 & 0.30 & 35.0 & 4.40 \\
\hline L3 & 19.8 & 450 & 0.22 & 50.8 & 4.09 \\
\hline L4 & 19.5 & 580 & 0.29 & 37.7 & 4.28 \\
\hline L5 & 17.9 & 552 & 0.26 & 45.0 & 4.10 \\
\hline L6 & 18.1 & 413 & 0.20 & 41.0 & 3.97 \\
\hline L7 & 21.1 & 284 & 0.09 & 27.0 & 4.33 \\
\hline L8 & 20.3 & 223 & 0.05 & 42.2 & 3.72 \\
\hline L9 & 19.3 & 89 & 0.01 & 24.1 & 3.94 \\
\hline L10 & 19.4 & 261 & 0.06 & 42.3 & 3.92 \\
\hline L11 & 18.1 & 529 & 0.26 & 35.5 & 4.34 \\
\hline L12 & 19.1 & 398 & 0.14 & 25.5 & 4.30 \\
\hline L13 & 19.7 & 488 & 0.20 & 28.7 & 4.38 \\
\hline L14 & 17.9 & 383 & 0.13 & 59.4 & 3.77 \\
\hline L15 & 19.9 & 558 & 0.26 & 38.5 & 4.22 \\
\hline Mean & 19.1 & 398 & 0.17 & 37.8 & 4.11 \\
\hline SD & 1.1 & 147 & 0.10 & 9.4 & 0.23 \\
\hline $\mathrm{R} 1$ & 18.7 & 194 & 0.08 & 25.9 & 4.09 \\
\hline $\mathrm{R} 2$ & 17.9 & 200 & 0.10 & 31.8 & 4.04 \\
\hline R3 & 19.3 & 172 & 0.06 & 26.4 & 4.19 \\
\hline R4 & 17.4 & 187 & 0.06 & 41.9 & 3.81 \\
\hline R5 & 19.0 & 182 & 0.06 & 28.9 & 4.22 \\
\hline R6 & 19.4 & 203 & 0.08 & 38.1 & 3.86 \\
\hline R7 & 19.9 & 263 & 0.10 & 37.8 & 3.94 \\
\hline $\mathrm{R} 8$ & 19.8 & 165 & 0.05 & 33.8 & 3.91 \\
\hline R9 & 18.6 & 135 & 0.03 & 31.2 & 3.80 \\
\hline R10 & 20.2 & 266 & 0.03 & 32.1 & 4.08 \\
\hline R11 & 19.5 & 159 & 0.02 & 33.0 & 3.93 \\
\hline $\mathrm{R} 12$ & 21.1 & 151 & 0.02 & 26.6 & 3.91 \\
\hline
\end{tabular}


Table 1 continued

\begin{tabular}{|c|c|c|c|c|c|}
\hline Samples honey & Water content $(\%)$ & Electrical conductivity $(\mathrm{S} / \mathrm{cm})$ & Total ash content $(\%)$ & Free acidity $(\mathrm{meq} / \mathrm{kg})$ & $\mathrm{pH}$ \\
\hline $\mathrm{R} 13$ & 17.8 & 187 & 0.05 & 33.7 & 3.98 \\
\hline $\mathrm{R} 14$ & 21.3 & 187 & 0.06 & 33.2 & 4.08 \\
\hline $\mathrm{R} 15$ & 20.2 & 197 & 0.08 & 37.2 & 3.88 \\
\hline $\mathrm{R} 16$ & 20.6 & 165 & 0.05 & 33.0 & 3.80 \\
\hline $\mathrm{R} 17$ & 18.3 & 242 & 0.14 & 41.7 & 3.94 \\
\hline $\mathrm{R} 18$ & 20.1 & 152 & 0.05 & 31.4 & 3.92 \\
\hline R19 & 19.3 & 312 & 0.17 & 38.8 & 3.96 \\
\hline $\mathrm{R} 20$ & 20.3 & 275 & 0.16 & 31.9 & 4.20 \\
\hline Mean & 19.4 & 200 & 0.07 & 33.4 & 3.98 \\
\hline SD & 1.1 & 47 & 0.04 & 4.6 & 0.14 \\
\hline A1 & 18.9 & 153 & 0.03 & 33.8 & 3.75 \\
\hline A2 & 19.0 & 179 & 0.07 & 29.1 & 3.95 \\
\hline A3 & 20.2 & 57 & 0.01 & 20.4 & 3.99 \\
\hline A4 & 18.5 & 199 & 0.05 & 40.7 & 3.81 \\
\hline A5 & 18.5 & 145 & 0.03 & 27.8 & 3.84 \\
\hline A6 & 20.1 & 198 & 0.10 & 28.1 & 3.78 \\
\hline Mean & 19.2 & 155 & 0.05 & 30.0 & 3.85 \\
\hline SD & 0.8 & 50 & 0.03 & 6.4 & 0.10 \\
\hline
\end{tabular}

whereas in samples of rapeseed and acacia honeys they were significantly lower and reached $200 \mathrm{~S} / \mathrm{cm}$ and 155 $\mathrm{S} / \mathrm{cm}$, respectively. These results enable concluding that the electrical conductivity may be a reliable parameter for botanical discrimination of honeys. For example, acacia honey may be discriminated from the other honeys because it had the lowest mean value of this parameter.

Ash content of honey is indicative of the contents of its mineral compounds. It is claimed to be a criterion of honey quality and a parameter enabling discrimination between nectar and honeydew honey as the latter contains more minerals (Pita-Calvo and Vázquez, 2017). It is assumed that ash content of nectar honeys should be lower or equal to $0.6 \%$ (w/w) (El Sohaimy et al., 2015; Habib et al., 2014). Results obtained in our study ( $0.01 \%$ to $0.37 \%$ ) (Table 1$)$, fit within the above level, which may point to the purity of samples and probable lack of their adulteration with molasses.

Free acidity is a measure of honey condition deterioration. This parameter is linked with the natural presence of organic acids in honey, which remain in equilibrium with internal esters, lactones and some inorganic ions like: phosphates, sulfates and chlorides. In addition, a high value of total acidity may imply that at some point the honey began to ferment and that the produced alcohol was transformed into organic acids (Grigoryan, 2016). Pursuant to the Codex Alimentarius (2001) and EU Directive (Council EU, 2001), the permissible value of free acidity in honeys is at $50 \mathrm{meq} / \mathrm{kg}$. Results of free acidity analysis were presented in Table 1. Its highest mean value was found in buckwheat honey $(68.3 \mathrm{meq} / \mathrm{kg})$. Out of 17 analyzed buckwheat honeys, only two did not exceed the maximum permissible value set in the international and European standards (B11-28.7 meq/kg - and B17$42.8 \mathrm{meq} / \mathrm{kg}$ ). In the other honey varieties, the mean value of free acidity was lower than the permissible value and reached $37.8 \mathrm{meq} / \mathrm{kg}$ in linden honeys, $33.4 \mathrm{meq} / \mathrm{kg}$ in rapeseed honeys, and $30.0 \mathrm{meq} / \mathrm{kg}$ in acacia honeys. The above results allow concluding that the light honeys-including linden, rapeseed and acacia honeys-are characterized by a considerably lower content of organic acids compared to the dark honeys represented in our study by buckwheat honeys. Some authors (Fechner et al., 2016) suggest that free acidity might be used to discriminate nectar and honeydew honeys, however this was not confirmed by Oroian and Ropciuc (2017) who determined higher values of active acidity in nectar than in honeydew honeys.

Honey is an acidic food product which contains both organic acids and amino acids, and variability of its acidity which depends on its botanical origin may result from the presence of these two groups of chemical compounds 
(Oroian, 2012). The $\mathrm{pH}$ value of honey is correlated with its storage and with the growth of microorganisms capable of changing honey texture and stability. Although the EU Directive (Council EU, 2001) does not set any pH standards for honeys, its value should be low to prevent microbiological spoilage. The $\mathrm{pH}$ values of honeys usually range from 3.5 to 5.5 and are due to the presence of organic acid, gluconic acid in particular, and inorganic ions like phosphates and chlorides (Pita-Calvo and Vázquez, 2017). Results of $\mathrm{pH}$ measurements conducted in the analyzed honeys were presented in Table 1 . The highest mean $\mathrm{pH}$ value (4.11) was determined for linden honeys. In turn, the mean $\mathrm{pH}$ value of buckwheat honeys accounted for 3.89, that of rapeseed honeys-for 3.98, and that of acacia honeys was the lowest and reached 3.85. The low $\mathrm{pH}$ value of honey determines its microbiological stability and may indicate high contents of minerals (El Sohaimy et al., 2015). This thesis was confirmed in our study because linden honeys had the highest $\mathrm{pH}$ value and the highest total ash content.

Electrical conductivity of honeys is strongly correlated with the concentration of their mineral salts, organic acids and proteins. It shows the greatest variability among the physicochemical parameters of honeys depending on their botanical origin (Fechner et al., 2016; Grigoryan, 2016). In our study, we were looking for a correlation between ash content and electrical conductivity of the analyzed nectar honeys, because conductivity corresponds well with content of minerals in honeys, i.e. the higher the ash content, the higher the conductivity is. This statement was confirmed by a correlation depicted in Fig. 1. In the case of the analyzed nectar honeys, the correlation coefficient reached 0.934 , which is indicative of a very strong linear correlation between these two variables. The above results are

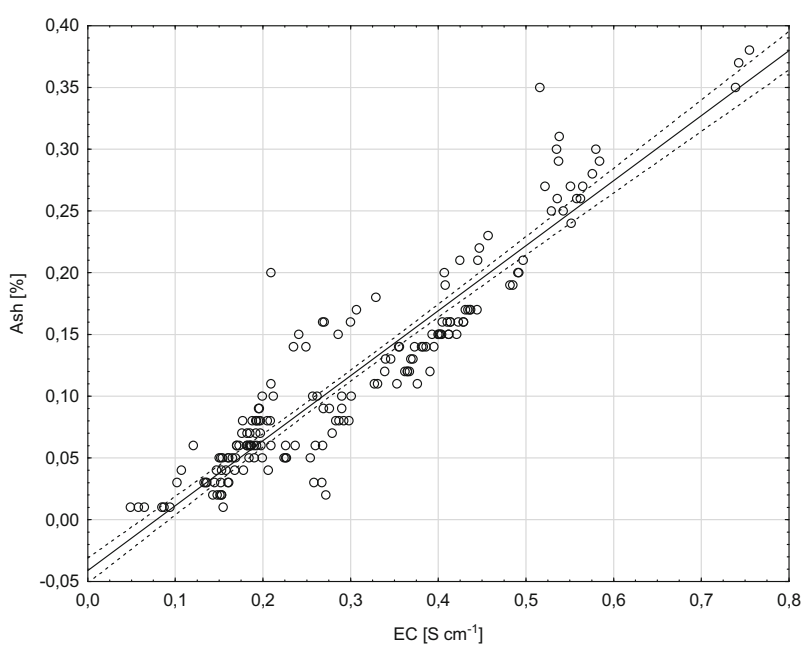

Fig. 1 Correlation between electrical conductivity (EC) and ash content (confidence level 95\%) consistent with literature data. A linear correlation $(r=0.99)$ was also found in our another research (Majewska and Kowalska, 2011) carried out with Polish nectar honeys. A linear correlation between ash content and electrical conductivity was also reported for Indian nectar honeys ( $r=0.98$ ) (Saxena et al., 2010). Such correlations between these two parameters has led to a situation in which electrical conductivity replaced ash content in the international (Codex Alimentarius, 2001) and European (Council EU, 2001) standards concerning evaluation of honeybee honey quality. At the same time, it has become the most frequently applied method for honey origin identification.

The cluster analysis (CA) conducted with the Ward method indicated botanical similarity of honey samples depending on their physicochemical parameters. The obtained dendrogram (Fig. 2), which depicts similarity of the analyzed physicochemical parameters, allowed distinguishing two clusters of parameters: the first one included electrical conductivity, ash content and $\mathrm{pH}$ of honeys, whereas the second one included only one parameter, namely content of free acids. Water content is a parameter which directly depends on many factors including weather conditions in the period of nectar harvest and degree of honey maturity. For this reason, this variable was not treated as a significant criterion in comparison of honeys originating from various plant sources.

Apart from the cluster analysis, we conducted also the principal component analysis (PCA). The appropriate number of principal components was selected based on the analysis of a scree plot made for the investigated honeys. It was found advisable to reduce four variables to two principal components that would together explain $93.6 \%$ of total variability of data. The first principal component (PC1) explained 59.45\% while the second one (PC2) explained $34.15 \%$ of data variability. Values of coefficients

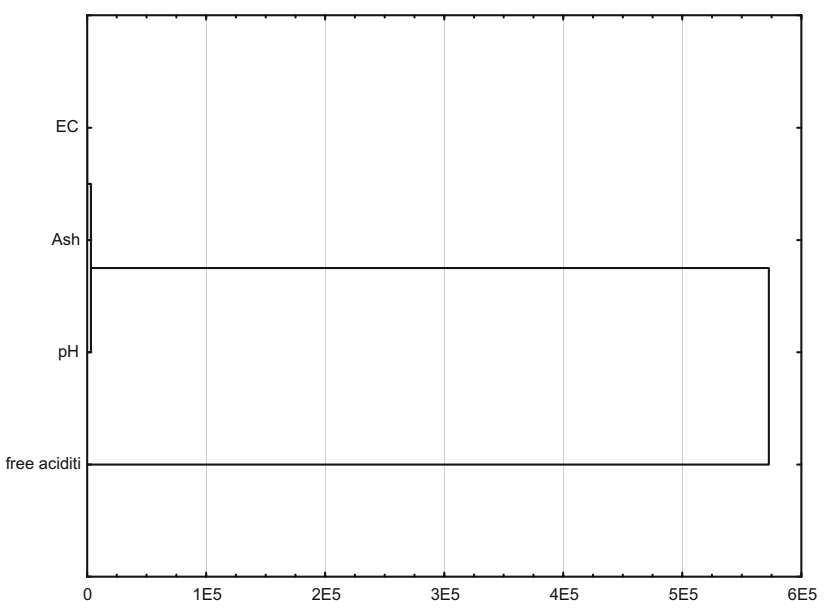

Fig. 2 Dendrogram of variables (elements) 
Table 2 Loadings of variables for the two PCs (principal components) — in bold are the significant loadings used for each principal component

\begin{tabular}{llr}
\hline Variable & PC1 & \multicolumn{1}{l}{ PC2 } \\
\hline EC & $\mathbf{0 . 9 8 6}$ & -0.022 \\
Ash & $\mathbf{0 . 9 5 9}$ & 0.094 \\
Free acids & 0.554 & $-\mathbf{0 . 7 8 3}$ \\
pH & 0.424 & $\mathbf{0 . 8 6 2}$ \\
\hline
\end{tabular}

of correlation (Table 2) between the variables and the principal components indicated that the first component (PC1) was strongly correlated with ash content and electrical conductivity of honey, and that the second component (PC2) was positively correlated with honey $\mathrm{pH}$ and negatively correlated with the content of free acids.

Figure $3 \mathrm{~B}$ presents the projection of the analyzed honeys onto a plane marked by two principal components PC1 and PC2, whereas Fig. 3A depicts projection of the studied variables onto the same plane. When analyzing the area marked by the two selected components it was observed that the investigated honeys could be divided into groups associated with their botanical origin (Fig. 3B). Three clusters of honeys were distinguished: linden, buckwheat and others, i.e. acacia and rapeseed. In the case of both linden and buckwheat honeys, single samples appeared outside the cluster characterizing a given group of honeys. Points depicting buckwheat honeys were in most cases highly concentrated in the cluster, which was indicative of a low internal variability of these samples. In turn, samples of linden honeys were more diversified, which was indicated by greater scattering of points in the area characteristic for this honey variety. Figure $3 \mathrm{~A}$ shows that the most important parameters used in these analyses, which enabled botanical discrimination of honeys, was their electrical conductivity and ash content. The two other parameters ( $\mathrm{pH}$ and content of free acids) played a less significant role in botanical identification of the analyzed honeys. Unfortunately, these parameters did not allow for botanical discrimination of the other honeys: acacia and rapeseed ones, because no separate clusters were distinguished for these varieties in the plane marked by PC1 and PC2. Points depicting these samples showed low internal variability, which was indicated by a high concentration within the cluster.

The analysis of correlation coefficients between variables and principal components (Table 2) and of projections of particular variables and the studied honeys onto the plane marked by the two first principal components (Fig. 3) enabled concluding that the key variables for the classification of the botanical origin of Polish nectar honeys could be electrical conductivity and ash content, followed by free acid content and $\mathrm{pH}$ of honeys. The importance of these parameters in the botanical classification of nectar honeys was also emphasized by authors from other countries (Silvano et al., 2014).

In conclusion, out of the 58 analyzed samples of honey, water content was exceeded in 13 samples-mainly of rapeseed honeys. Unfortunately, in the case of buckwheat honeys, the most unfavorable parameter turned out to be their free acidity as only two of the 17 analyzed honeys of this variety did not exceeded the permitted values set in legal regulations, which may be indicative of a low quality of honeys of this variety. A correlation was also analyzed between particular physicochemical parameters of honeys and a strong positive correlation $(r=0.934)$ was found

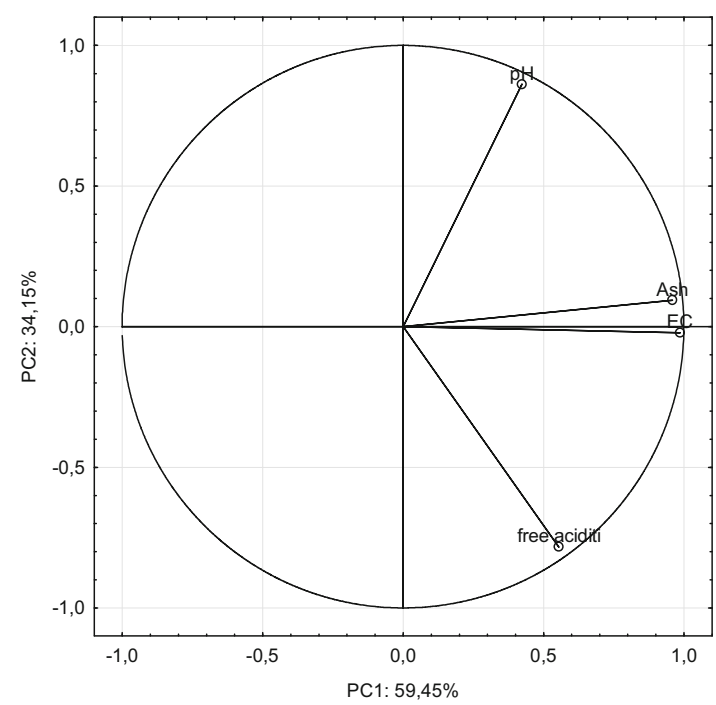

(A)

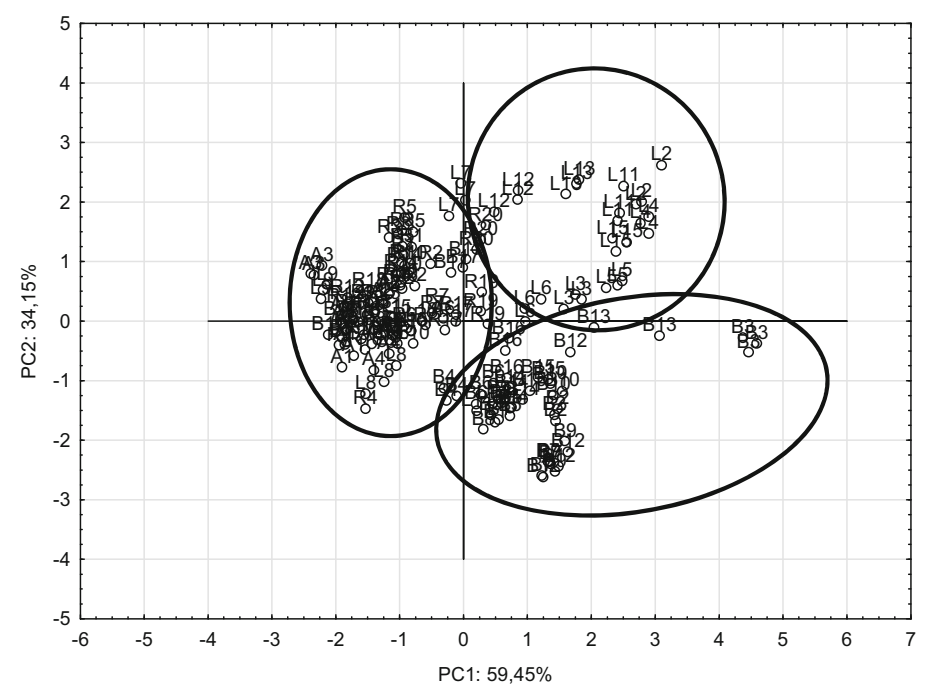

(B)

Fig. 3 Representation of the variables (A) and honey samples (B) as functions of the PC1 versus PC2 
between their ash content and electrical conductivity, i.e. parameters associated with the content of minerals. The strong positive correlation between electrical conductivity and ash content enables fast determination of total minerals content in honeys using conductometry. The chemometric analysis of the results of physicochemical parameter determinations demonstrated that electrical conductivity and ash content are also the most reliable markers in determining the botanical origin of linden and buckwheat honeys. Unfortunately, they appear insufficient for reliable identification of acacia and rapeseed honeys.

Acknowledgements Thanks are due to all the beekeepers who have provided the honey samples of this study.

\section{Compliance with ethical standards}

Conflict of interest The authors declare no conflict of interest.

Open Access This article is distributed under the terms of the Creative Commons Attribution 4.0 International License (http://crea tivecommons.org/licenses/by/4.0/), which permits unrestricted use, distribution, and reproduction in any medium, provided you give appropriate credit to the original author(s) and the source, provide a link to the Creative Commons license, and indicate if changes were made.

\section{References}

Bueno-Costa FM, Zambiazi RC, Bohmer BW, Chaves FC, da Silva WP, Zanusso JT, Dutra I. Antibacterial and antioxidant activity of honey from the state of Rio Grande do Sul, Brazil. LWT Food Sci. Technol. 65: 333-340 (2016)

Codex Alimentarius. Revised Codex standard for honey: Codex standard 12-1981. Rev.1 (1987), Rev.2 (2001)

Council EU. Council directive 2001/110/EC of 20 December 2001 relating to honey. Off. J. Eur. Commun. L 10: 47-52 (2001)

El Sohaimy SA, Masry SHD, Shehata MG. Physicochemical characteristics of honey from different origins. Ann. Agric. Sci. 60: 279-287 (2015)

Fechner DC, Moresi AL, Riuz Díaz JD, Pellerano RG, Vazquez FA. Multivariate classification of honeys from Carrientes (Argentina) according to geographical origin based on physicochemical properties. Food Biosci. 15: 49-54 (2016)

Grigoryan K. Safety of honey. Vol. I, pp. 217-246. In: Regulating Safety of Traditional and Ethnic Foods. Prakash V, MartínBelloso O, Keener L, Astley SB, Braun S, McMahon $\mathrm{H}$, Lelieveld H (eds). Elsevier, Amsterdam (2016)

Habib HM, Al Meqbali FT, Kamal H, Souka UD, Ibrahim WH. Physicochemical and biochemical properties of honeys from arid region. Food Chem. 153: 35-43 (2014)

Jandrić Z, Haughey SA, Frew RD, McComb K, Galvin-King P, Elliott CT, Cannavan A. Discrimination of honey of different floral origin by a combination of various chemical parameters. Food Chem. 189: 52-59 (2015)

Juan-Borrás M, Domenech E, Hellebrandova M, Escriche I. Effect of country origin on physicochemical, sugar and volatile composition of acacia, sunflower and tilia honeys. Food Res. Int. 60: 86-94 (2014)

Karabagias IK, Vavoura MV, Nikolaou C, Badeka AV, Kontakos S, Kontominas MG. Floral authentication of Greek unifloral honeys based on the combination of phenolic compounds, physicochemical parameters and chemometrics. Food Res. Int. 62: 753-760 (2014)

Majewska E, Kowalska J. Badanie korelacji pomiędzy przewodnością elektrycznạ i zawartością popiołu w wybranych miodach pszczelich. Acta Agroph. 17: 369-376 (2011)

Oroian M. Physico-chemical and rheological properties of Romanian honeys. Food Biophys. 7: 296-307 (2012)

Oroian M. Influence of temperature, frequency and moisture content on honey viscoelastic parameters-neutral networks and adaptive neuro-fuzzy inference system prediction. LWT Food Sci. Technol. 63: 1309-1316 (2015)

Oroian M, Ropciuc S. Honey authentication based on physicochemical parameters and phenolic compounds. Comput. Electron. Agric. 138: 148-156 (2017)

Oroian M, Amariei S, Leahu A, Gutt G. Multi-elements composition of honey as a suitable tool for its authenticity analysis. Pol. J. Food Nutr. Sci. 62: 93-100 (2015)

Oroian M, Prisacaru A, Hretcanu EC, Stroe SG, Leahu A, Buculei A. Heavy metals profile in honey as a potential indicator of botanical and geographical origin. Int. J. Food Prop. 19: 1825-1836 (2016)

Pita-Calvo C, Vázquez M. Differences between honeydew and blossom honeys: a review. Trend Food Sci. Technol. 59: 79-87 (2017)

Popek S, Halagarda M, Kursa K. A new model to identify botanical origin Polish honeys based on the physicochemical parameters and chemometric analysis. LWT Food Sci. Technol. 77: 482-487 (2017)

Rodríguez Flores MS, Escuredi O, Seijo MC. Assessment of physicochemical and antioxidant characteristics of Quercus pyrenaica honeydew honeys. Food Chem. 166: 101-106 (2015)

Saxena S, Gautam S, Sharma A. Physical, biochemical and antioxidant properties of some Indian honeys. Food Chem. 118: 391-397 (2010)

Silvano MF, Varela MS, Palacio MA, Ruffinengo S, Yamul DK. Physicochemical parameters and sensory properties of honeys from Buenos Aires region. Food Chem. 152: 500-507 (2014)

Simeonov V, Wolska L, Kuczynska A, Gurwin J, Tsakovski S, Protasowicki M, Namiesnik J. Sediment-quality assessment by intelligent data analysis. Trend Anal. Chem. 26: 323-331 (2007)

Wang J, Qing XL. Chemical composition, characterization and differentiation of honey botanical and geographical origins. Vol. 62, pp. 89-137. In: Advances in Food and Nutrition Research. Taylor SL (ed). Elsevier Inc., Waltham, MA, USA (2011)

Publisher's Note Springer Nature remains neutral with regard to jurisdictional claims in published maps and institutional affiliations. 